\title{
LUMOliero - Suomen peltojen lieroyhteisöjen peruskartoitus (2004-2006)
}

Visa Nuutinen ${ }^{1)}$, Juhani Terhivuo ${ }^{2)}$, Mervi Nieminen ${ }^{1)}$, Elise Ketoja ${ }^{1)}$ ja Taisto Sirén ${ }^{1)}$

${ }^{1)}$ MTT (Maa- ja elintarviketalouden tutkimuskeskus),31600 Jokioinen, etunimi.sukunimi@mtt.fi

2) Luonnontieteellinen keskusmuseo, Eläinmuseo, PL 26 (Teollisuuskatu 23), 00014 Helsingin yliopisto,juhani.terhivuo@helsinki.fi

\section{Tiivistelmä}

Tämän Monimuotoisuuden tutkimusohjelmaan (MOSSE 2003-2006) kuuluvan hankkeen tavoitteena on lisätä tietämystä suomalaisen viljelymaan biologisesta monimuotoisuudesta, siihen vaikuttavista tekijöistä sekä monimuotoisuuden toiminnallisesta merkityksestä. Tutkimuskohteena ovat peltomaan lierot. Lieroyhteisöjen alueellisesta vaihtelusta muodostetaan kokonaiskuva pyrkien tunnistamaan vaihtelua aiheuttavat avaintekijät. Tuloksia käytetään hyväksi ennakoitaessa lieroyhteisön vastetta viljelytapojen muutoksiin sekä kehitettäessä viljelymaan laadun arviointimenetelmiä. Hankkeen ensimmäisessä vaiheessa koottiin yhteen aikaisemmat tutkimustulokset lierojen esiintymisestä suomalaisissa peltomaissa. Syksyjen 2004 ja 2005 aikana toteutetulla kenttäturneella koottiin entistä kattavampi aineisto lieroyhteisöjen maantieteellisestä vaihtelusta hyödyntäen MTT:n toimipaikoilla 1990-luvulla aloitetun maaperäseurannan näytepisteverkkoa. Näytteenotto tehtiin yhdellätoista paikkakunnalla (eteläisin Mietoinen, pohjoisin Rovaniemi), kaikkiaan tutkittuja peltoja oli 53. Näytteitä otettiin sekä lohkon viljellyllä osalla että piennaralueella. Näytteenoton yhteydessä kerättiin lisäksi tietoa lierojen merkityksestä peltomaan huokosrakenteelle. Lierojen runsaudenvaihtelun ja yhteisöjen lajikoostumuksen vaihtelun selittämiseksi aineisto yhdistetään näytepisteistä aiemmin kerättyyn tietoon maalajista ja maan kemiallisista ominaisuuksista sekä pellonkäyttötietoihin. Lieroaineisto museoidaan ja liitetään Luonnontieteellisen keskusmuseon kokoelmiin ja tietojärjestelmään kansalliseksi referenssiaineistoksi. Tutkimus pyrkii olemaan avaus viljelymaan laadun biologiselle seurannalle Suomessa. Tavoitteena on, että kenttäkartoitus olisi alku lieroseurannalle, joka tultaisiin toistamaan näytepisteissä noin 10 vuoden välein. Esittelemme tutkimuksen lähtökohtia, työtapoja ja hankkeen ensivaiheen alustavia tuloksia

Asiasanat: biodiversiteetti, lierot, eliömaantiede, ekosysteemipalvelut, viljelymaan laatu, kartoitus, seuranta 


\section{Johdanto}

Maaperäeliöiden monimuotoisuus liittyy läheisesti viljelymaan tarjoamiin ekosysteemipalveluihin (Brussaard ym. 1997). Tämä pätee hyvin lieroihin, jotka vaikuttavat maaperän fysikaalisten ominaisuuksien muodostumiseen ja vesitalouteen sekä säätelevät osaltaan maan orgaanisen aineksen hajoamista sekä kasviravinteiden mineralisaatiota (Linden ym. 1994). Suomen lierolajisto koostuu vajaasta kahdestakymmenestä lajista, joista noin puolet on tavattu peltomaassa. Viljelymaassa elävät lierolajit poikkeavat toisistaan elintavoiltaan ja eri ekologisiin lajiryhmiin kuuluvat lajit eivät ole toisiaan korvaavia maaperän toiminnallisten ominaisuuksien kannalta.

Eliöyhteisöjen piirteet syntyvät paikallisten ja alueellisten tekijöiden yhteisvaikutuksen tuloksena (Ricklefs 1987). Paikallisten viljely- ja maanhoitotoimenpiteiden vaikutuksista suomalaisen peltomaan lieroyhteisöön on saatavilla tutkimustietoa (esim. Nuutinen 1992, Palojärvi ym. 2002, Kukkonen ym. 2004b), mutta tietämys monien maaperän perusominaisuuksien ja lierojen esiintymisen suhteesta on edelleen hyvin puutteellista. Esimerkiksi eri maalajien merkitystä lierolajien esiintymiselle ei tunneta. Tietämys alueellisten tekijöiden merkityksestä on sekin hyvin puutteellista: lierolajien levinneisyyden pääpiirteet Suomen luonnonvaraisissa biotoopeissa tunnetaan (Terhivuo 1988), mutta peltoympäristöjä koskeva alueellisen mittakaavan tietämys puuttuu.

Tarve ennakoida lieroyhteisön vastetta viljelytapojen muutoksiin on lisääntynyt maaperän biologisiin prosesseihin nojaavien viljelytapojen yleistyessä. Esimerkiksi yleistyvässä kevennetyssä maanmuokkauksessa ja suorakylvössä lieroilla on tärkeä rooli maan kasvukunnon ylläpidossa (Alakukku ym. 2004). Samaten luonnonmukaisessa viljelyssä lierojen työn merkitys korostuu. Lierovasteen ennustamista kuitenkin vaikeuttaa tiedonpuute lierojen esiintymiseen vaikuttavista tekijöistä. Lieroja pidetään myös potentiaalisina viljelymaan laadun ilmentäjinä niin viljelymaan monitoroinnin kansainvälisessä kehitystyössä (Francaviglia 2004) kuin myös maatalousneuvonnan työkaluiksi kehitteillä olevissa tilatesteissä (Kukkonen ym. 2004a). Lierojen indikaattorikäyttö edellyttää sekin yksityiskohtaisempaa perustietoa lierojen runsautta ja levinneisyyttä kontrolloivista tekijöistä.

LUMOliero-hanke pyrkii vastaamaan näihin tiedontarpeisiin. Tutkimuksen tavoitteena on muodostaa kokonaiskuva peltomaiden lieroyhteisöjen alueellisesta vaihtelusta Suomessa ja tunnistaa vaihtelua aiheuttavat avaintekijät. Yhtenä käytännöllisenä tavoitteena on haarukoida lierorunsauden vertailuarvoja eri tyyppisille viljelymaille maan eri osissa. Hankkeessa kootaan yhteen olemassaoleva tietämys lierolajien esiintymisestä peltomaassa sekä kerätään alueellisesti entistä kattavampi kenttäaineisto peltojen lieroyhteisöjen vaihtelusta. Kenttätyö tehdään hyödyntäen aiemmin MTT:n tutkimusasemille perustetun maaperäseurannan näytepisteverkkoa, mikä mahdollistaa lierolajien runsaudenvaihtelun suhteuttamisen maaperän muuhun vaihteluun sekä peltojen viljelyhistoriaan. Tavoitteena on, että tutkimus olisi samalla alku viljelymaan laadun biologiselle seurannalle Suomessa.

Tutkimus painottaa biologisen monimuotoisuuden hyödyntämistä kehitettäessä viljelyä ekologisesti ja taloudellisesti kestävään suuntaan ja hanke tähtää käytännön maanhoidossa hyödylliseen tietoon. Tutkimus pyrkii kuitenkin hyödyttämään myös perustutkimusta. Syntyvät uudet aineistot tullaan dokumentoimaan huolellisesti ja säilömään Luonnontieteelliseen keskusmuseoon (LTKM) kuuluvan Eläinmuseon kokoelmiin sekä liittämään LTKM:n tietojärjestelmään. Kertynyttä aineistoa voidaan näin käyttää myöhemmissä taksonomisissa tutkimuksissa sekä eliömaantieteellisten ja ekologisten hypoteesien testaamisessa.

Aineistojen määritykset ja mittaukset sekä tilastollinen analyysi ovat vielä kesken. Teemme seuraavassa katsauksen hankeen työmenetelmiin ja ensivaiheen alustaviin tuloksiin.

\footnotetext{
Aineisto ja menetelmät

Tutkimuksen ensimmäisessä vaiheessa koottiin yhteen olemassa oleva tutkimustieto peltojen lieroyhteisöjen alueellisesta vaihtelusta Suomessa. Lähteenä käytettiin tutkimusjulkaisuja sekä julkaisemattomia, eri tutkijoilta saatuja aineistoja. Näytteenottomenetelmien kirjavuuden vuoksi arvioita lierojen tiheydestä tai biomassassasta ei käytetty, ainoastaan tieto lajien esiintymisestä kirjattiin. Lisäksi koottiin saatavilla oleva tieto tutkimuspaikkojen maaperän ominaisuuksista sekä pellonkäytöstä.

Hankkeen kenttätyöosassa kartoitetaan peltomaan lieroyhteisöjen maantieteellinen vaihtelu hyödyntäen Maa- ja elintarviketalouden tutkimuskeskuksen (MTT) tutkimusasemillaan vuonna 1992 käynnistämän maaperäseurannan näytepisteverkkoa (Kuva 1b, Urvas 1995, Sippola ym. 2001).
} 
Näytepaikoilta aiemmin kerätty laaja aineisto maalajin ja maan kemiallisten ominaisuuksien vaihtelusta yhdistetään lieroaineistoon selvitettäessä lieroyhteisöjen koostumukseen vaikuttavia tekijöitä. Peltojen viljelyhistoriaa koskeva tieto kootaan tutkimusasemien viljelykirjanpidosta.

Kenttätutkimukseen valittiin mukaan 11 MTT:n toimipaikkaa, jotka olivat jatkamassa toimintaansa vuonna 2003 saatavilla olleen tiedon perusteela. Koska eloperäisten maiden osuus oli aineistossa pieni, rajoitettiin tutkimus koskemaan kivennäismaita. Kaikkiaan tutkittavaksi valittiin 53 eri pelloilla sijaitsevaa pistettä. Pisteiden valinnassa pyrittiin siihen, että kultakin paikkakunnalta tulisi mukaan maan savespitoisuuden ja orgaanisen aineksen pitoisuuden suhteen mahdollisimman laaja kirjo peltoja. Näitä muuttujia pidettiin aiempien, muualla tehtyjen tutkimusten perusteella potentiaalisimpina lieroyhteisön vaihtelun selittäjinä (Joschko ym. 2002). Kullakin paikkakunnalla otettiin näytteitä 46:1la eri peltolohkolla sijaitsevan seurantapisteen ympäriltä. Poikkeuksen muodosti Toholampi, jossa tutkittuja pisteitä oli vain yksi. Vallitseva pellonkäyttö näytepisteissä oli viljanviljely tai nurmi, valtaosan edustaessa "tavanomaista" viljelyä. Syksyn 2004 näytteenotto tehtiin viidellä sellaisella paikkakunnalla, joissa löytyi erityisen suurta vaihtelua maaperän oletetuissa avainmuuttujissa. Syksyllä 2005 näytteenotto tehtiin lopulla kuudella paikkakunnalla. Kumpanakin vuonna näytteenotto tapahtui elokuun lopun ja lokakuun puolenvälin välisenä aikana.

Ennen näytteenottoa kunkin seurantapisteen ympärille merkittiin tasasivuisen kolmion (sivu $5 \mathrm{~m}$ ) kärkipisteet. Lieronäytteet otettiin niistä yhdistetyllä maan käsinlajittelu - formaliini -menetelmällä. Menetelmä vastaa pian valmistuvaa lieronäytteenoton ISO-standardia. Lierojen fysikaalisten maaperävaikutusten tutkimiseksi laskettiin samassa yhteydessä lieronkäytävien määrä $20 \mathrm{~cm}: n$ syvyydestä. Jotta saataisiin kattava kuva paikallisesta lajimäärästä, otettiin lähimmältä näytteenottoon soveltuneelta piennaralueelta kolme lieronäytettä viiden metrin välein. Kentällä lierot säilöttiin formaliinin ja alkoholin seokseen, josta ne ennen määrityksiä ja mittauksia siirrettiin alkoholiin. Määritetty materiaali ryhmiteltiin valmiiksi aineiston museointia varten.

Koska näytteenotot ajoittuivat kahdelle vuodelle, haluttiin saada käsitys lierojen ajallisen runsaudenvaihtelun suuruudesta tutkimuksen aikana. Tarkoitusta varten lierojen runsaus mitattiin vuosina 2003-2005 samaan aikaan syyskuuta yhdeksässä pisteessä Jokioisissa sijaitsevalla peltolohkolla, joka koko tutkimuksen ajan oli nurmella.

a.

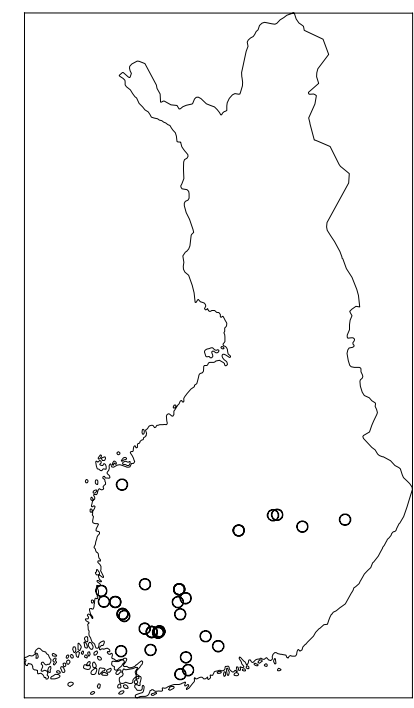

b.

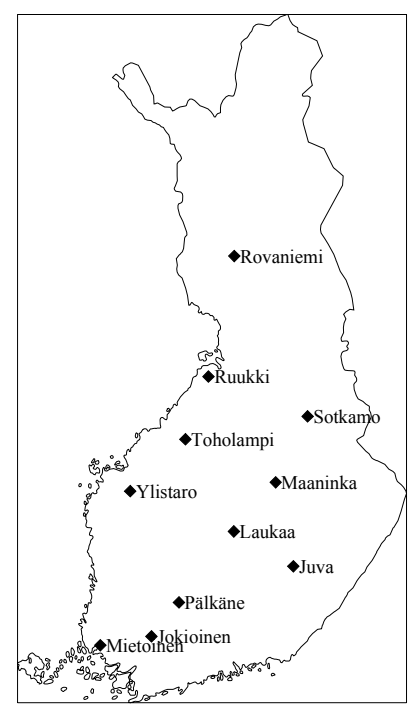

Kuva. 1. a. Aiemmat tutkimukset lierojen esiintymisestä peltomaassa. b. LUMOliero -hankkeen tutkimuspaikkakunnat.

\section{Tulokset ja tulosten tarkastelu}

\section{Lierolajien esiintyminen aiemmissa tutkimuksissa}

Aiemmin kerättyä luotettavaa tietoa lierolajien esiintymisestä löydettiin 36:Ita pellolta. Ne sijaitsevat 24:n kunnan alueella, valtaosin Lounais-Suomessa (Kuva 1a). Eteläisin pelto on Kirkkonummella, 
pohjoisin Laihialla. Suurin osa pelloista oli savimaita ja pellon tavallisin käyttö oli tavanomaisesti viljelty nurmi-viljakierto. Lierolajeja esiintyi aineistossa yhdeksän kappaletta, pelto-, onki- ja kastelieron ollessa yleisimmät lajit (Kuva 2). Lieroyhteisön lajimäärä vaihteli yhdestä seitsemään tavallisimman lajimäärän ollessa neljä.

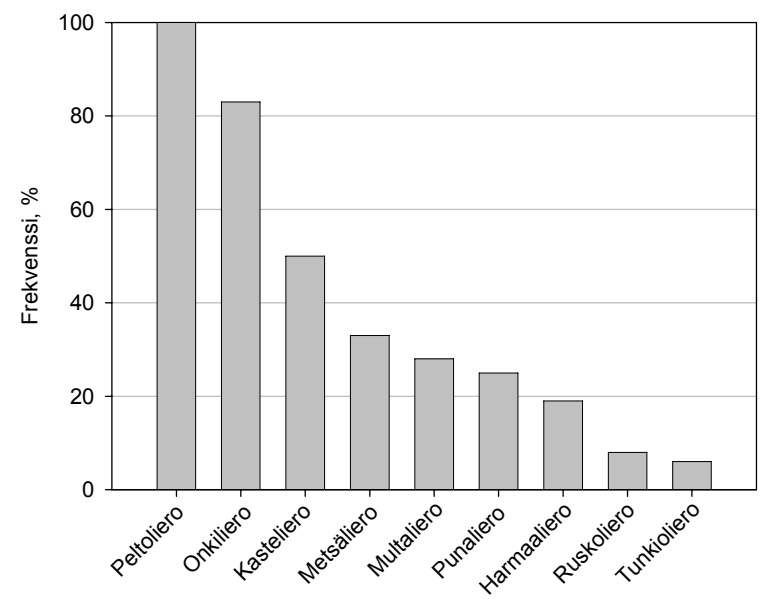

Kuva 2. Lierojen esiintymisfrekvenssi aiemmin tutkittujen peltojen lieroyhteisöissä ( $\mathrm{N}=36)$.

\section{Tuloksia syksyn 2004 näytteenotosta}

Vain yhdellä syksyllä 2004 tutkituista 29:stä peltolohkosta lieroja ei esiintynyt lainkaan pellon viljellyllä osalla. Kaikilta pientareilta lieroja löydettiin. Kaikkiaan aineistossa esiintyi yhdeksän lierolajia (Taulukko 1). Keskimääräinen lajilukumäärä oli pellolla kaksi lajia (minimi: 1, maksimi: 5) ja pientareella neljä lajia (min: 2, maks: 8). Lajeista kolme (pelto-, onki- ja kasteliero) esiintyi jokaisella paikkakunnalla sekä pellolla että pientareella. Selkein ero pellon ja pientareen välillä oli kolmen pintakarikkeen lierolajin (rusko-, metsä- ja punaliero) esiintymisen rajoittuminen pientareelle. Viherlieroja löydettiin vain lounaisimmalta tutkimuspaikkakunnalta (Mietoinen), mikä vastaa aiempien luonnonbiotoopeissa tehtyjen tutkimusten antamaa kuvaa lajin levinneisyydestä Suomessa. Pellolla olivat vallitsevina peltolieron kaltaiset pintamaan lajit, pientareella pintakarikkeen lajien ja kastelierojen osuus oli suurempi (Kuva 3).

Pellolla lierojen keskimääräinen tiheys oli 112 yksilöä $\mathrm{m}^{-2}$ (min: 0, maks: 1036) ja massa 104 grammaa $\mathrm{m}^{-2}$ (min: 0, maks: 316). Luvut ovat varsin korkeita, keskimääräisen runsauden vastatessa runsasta miljoonaa lieroyksilöä ja yli tonnin biomassaa hehtaarilla. Pientareella runsaus oli keskimäärin noin kaksi kertaa korkeampi, 264 yksilöä ja 196 grammaa $\mathrm{m}^{-2}$. Vain Mietoisissa lierojen kokonaistiheys ei pientareella ollut korkeampi kuin pellolla (Kuva 4).

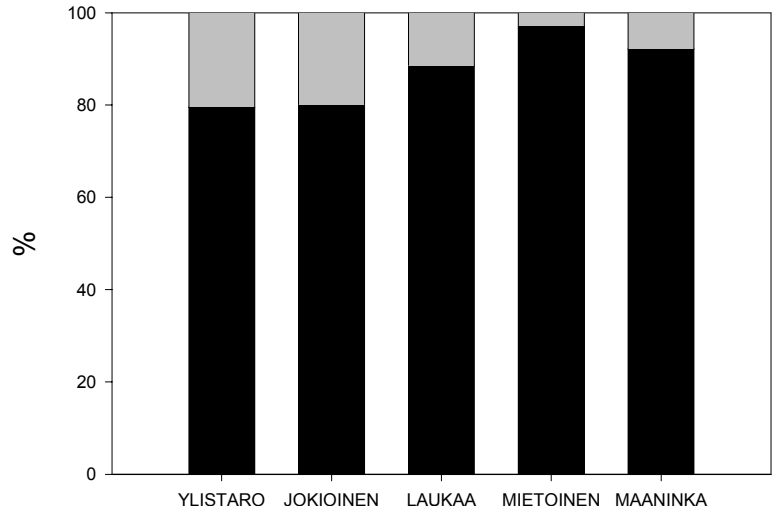

a.

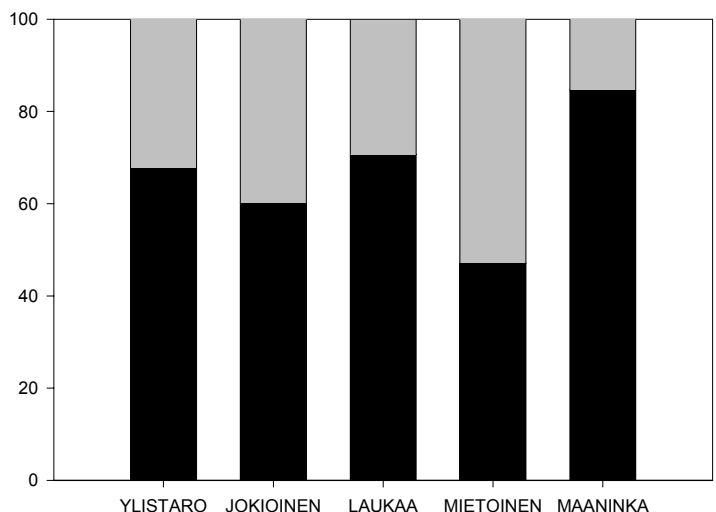

b.

Kuva 3. Pintamaan lierolajien (musta) ja pintakarikkeesssa elävien lajien + kastelierojen (harmaa) osuus lierojen yksilömäärästä pellolla (a) ja pientareella (b). 
Taulukko 1. Lierolajien esiintyminen syksyllä 2004 kerätyssä aineistossa. Musta pallo: laji esiintyy.

\begin{tabular}{|c|c|c|c|c|c|c|c|c|c|c|}
\hline & \multicolumn{5}{|c|}{ PELTO } & \multicolumn{5}{|c|}{ PIENNAR } \\
\hline $\begin{array}{l}\text { PAIKKAKUNNAT'1 } \\
\text { Pintamaan lajit } \\
\text { ("endogeeiset") }\end{array}$ & LOU & JOK & LAU & EPO & PSA & LOU & JOK & LAU & EPO & PSA \\
\hline Peltoliero & $\bullet$ & $\bullet$ & $\bullet$ & $\bullet$ & $\bullet$ & $\bullet$ & $\bullet$ & $\bullet$ & $\bullet$ & $\bullet$ \\
\hline Multaliero & & $\bullet$ & & $\bullet$ & $\bullet$ & $\bullet$ & $\bullet$ & & $\bullet$ & $\bullet$ \\
\hline Harmaaliero & $\bullet$ & & & & $\bullet$ & $\bullet$ & $\bullet$ & & & $\bullet$ \\
\hline Viherliero & $\bullet$ & & & & & $\bullet$ & & & & \\
\hline \multicolumn{11}{|l|}{$\begin{array}{c}\text { Pintakarikkeen lajit } \\
\text { ("epigeeiset") }\end{array}$} \\
\hline Onkiliero & $\bullet$ & $\bullet$ & $\bullet$ & $\bullet$ & $\bullet$ & $\bullet$ & $\bullet$ & $\bullet$ & $\bullet$ & $\bullet$ \\
\hline Ruskoliero & & & & & & $\bullet$ & $\bullet$ & & $\bullet$ & $\bullet$ \\
\hline Metsäliero & & & & & & $\bullet$ & $\bullet$ & $\bullet$ & $\bullet$ & $\bullet$ \\
\hline Punaliero & & & & & & & $\bullet$ & $\bullet$ & $\bullet$ & $\bullet$ \\
\hline \multicolumn{11}{|l|}{$\begin{array}{c}\text { Syvälle kaivautuvat } \\
\text { ("aneekkiset") }\end{array}$} \\
\hline Kasteliero & $\bullet$ & $\bullet$ & $\bullet$ & $\bullet$ & $\bullet$ & $\bullet$ & $\bullet$ & $\bullet$ & $\bullet$ & $\bullet$ \\
\hline
\end{tabular}

${ }^{1} \mathrm{LOU}=$ Mietoinen, JOK=Jokioinen, LAU=Laukaa, EPO=Ylistaro, PSA=Maaninka

Korkeimmat lierotiheydet mitattiin Maaningalla (Kuva 4), jossa peltolohkon korkein keskimääräinen lierotiheys oli yli 1000 yksilöä neliömetrillä (ks. Kuva 5). Näin korkeaa lierotiheyttä ei aiemmin ole havaittu tavanomaisesti viljellyssä suomalaisessa peltomaassa. Matalimmillaan pellon keskimääräinen lierotiheys oli Ylistarossa. Käynnissä olevassa aineiston tilastollisessa mallinnuksessa etsitään syitä lierojen runsaudenvaihtelulle suhteuttamalla runsaudet lohkojen maalajien eroihin, pellonkäyttöön sekä tutkimusalueiden luonnonmaantieteellisiin eroihin.

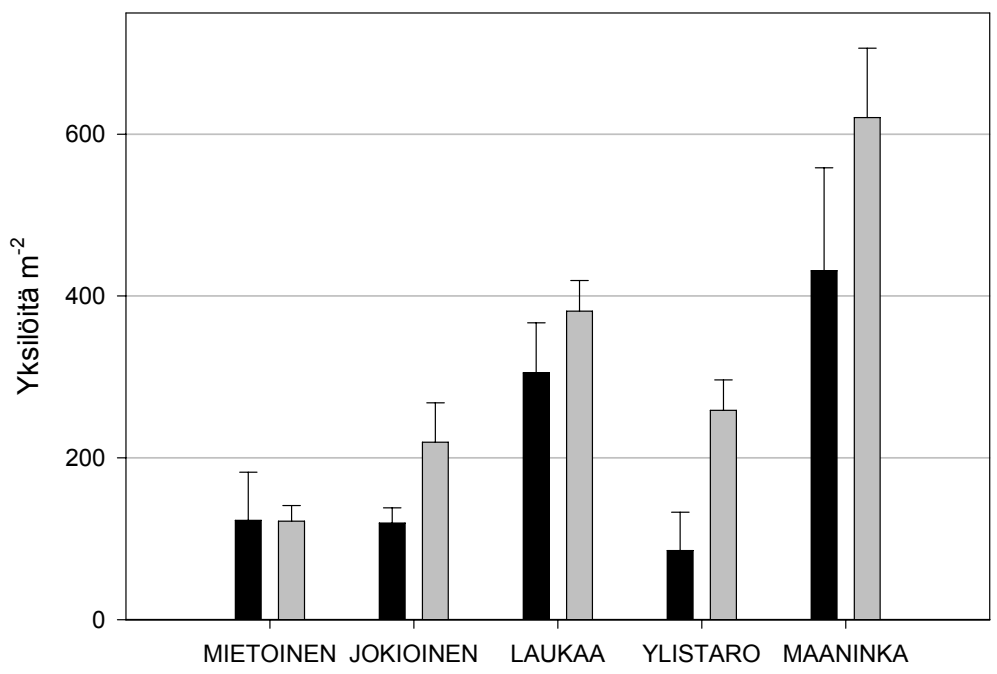

Kuva 4. Lierojen keskimääräinen yksilömäärä neliömetrillä pellolla (musta pylväs) ja pientareella (harmaa). Janat havavainnollistavat keskihajontoja / $\sqrt{ } \mathrm{n}$.

Lierojen runsauden ja näytekuopista laskettujen lieronkäytävien (=sylinterimäisten, halkaisijaltaan yli 2 mm:n maahuokosten) runsauden välillä oli varsin selkeä positiivinen vuorosuhde (Kuva 5). Aineistossa erottui joukko näytepisteitä, joissa suhteellisen alhaisellakin lierotiheydellä makrohuokosten määrä oli korkea. Pisteet sijaitsivat laidunlohkoilla, joilla maan vähäinen mekaaninen häirintä ilmeisesti tekee mahdolliseksi lierojen maata huokoistavan vaikutuksen kumuloitumisen. 


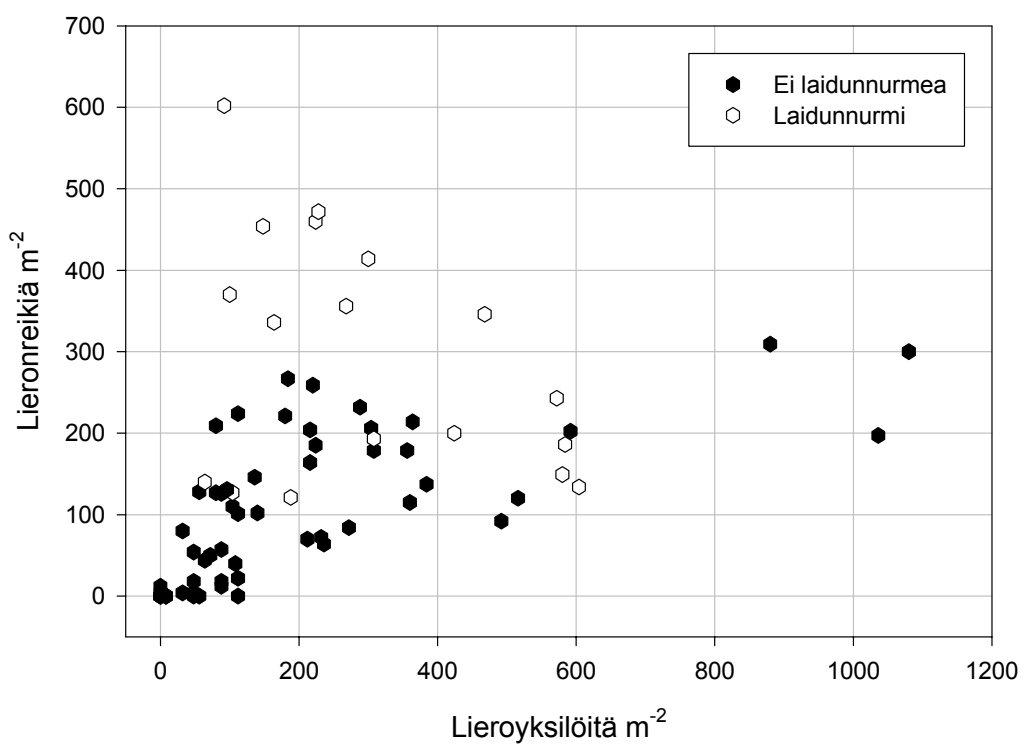

Kuva 5. Lierotiheyden ja lieronreikien määrän välinen vuorosuhde. Pisteet edustavat samassa näytepisteessä arvioitua lieroyksilöiden ja lieronreikien määrää. Arvio reikämäärälle perustuu kolmen laskijan tuloksen keskiarvoon. $\mathrm{N}=87$.

\section{Kiitokset}

Kiitämme yhteistyöstä: Oiva Hakala, Pekka Kivistö, Sanna Kukkonen, Esko Martikainen, Ritva Mäkelä-Kurtto, Jukka Salonen, Juha Tiainen, Markku Yli-Halla sekä MTT:n Alueellisen yksikön henkilökunta. Tutkimuksen on tehnyt mahdolliseksi Monimuotoisuuden tutkimusohjelma MOSSEn / Maa- ja metsätalousministeriön rahoitus.

\section{Kirjallisuus}

Alakukku, L., Mikkola, H. \& Teräväinen, H. (toim) 2004. Suorakylvöopas. Pro Agria Maaseutukeskusten liiton julkaisuja no. 1003. Tieto Tuottamaan 107: $91 \mathrm{~s}$.

Brussaard, L., Behan-Pelletier, V.M., Bignell, D.E., Brown, V.K., Didden, W., Folgarait, P., Fragoso, C., Wall Freckman, D., Gupta, V.V.S.R., Hattori, T., Hawksworth, D.L., Klopatek, C., Lavelle, P., Malloch, D.W., Rusek, J., Soderstrom, B., Tiedje, J.M. \& Virginia, R.A. 1997. Biodiversity and ecosystem functioning in soil. Ambio 26:563-570.

Francaviglia, R. (toim.) 2004. Agricultural Impacts on Soil erosion and Soil Biodiversity: Developing Indicators for Policy Analysis. Proceedings from OECD Expert Meeting - Rome Italy, March 2003, $654 \mathrm{~s}$.

Joschko, M., Lentsch, P., Krück, St., Fox, C. \& Tomlin, A. 2002. Relationship between mean earthworm abundance and soil chracteristics in German and Canadian agricultural soils - a model approach. The $7^{\text {th }}$ International Symposium on Earthworm Ecology, Cardiff, Wales, $1^{\text {st }}-6^{\text {th }}$ September 2002. Book of Abstracts, s. 317.

Kukkonen, S., Alakukku, L., Myllys, M. \& Palojärvi, A. 2004a. Tiloilla tapahtuva maan laadun arviointi. In: Hopponen, A. \& Rinne, M. Maataloustieteen Päivät 2004, 12.-13.1.2004 Viikki, Helsinki [: esitelmät ja posterit]. Suomen maataloustieteellisen seuran tiedote 19: $1 \mathrm{p}$. http://www.agronet.fi/maataloustieteellinenseura/julkaisut/posterit04/ym011.pdf

Kukkonen, S., Palojärvi, A., Räkköläinen, M. \& Vestberg, M. 2004b. Peat amendment and production of different crop plants affect earthworm populations in field soil. Soil Biology and Biochemistry 36: 415423

Linden, D.R., Hendrix, P.F., Coleman, D.C. \& van Vliet, P.C.J. 1994. Faunal indicators of soil quality. Sivut 91-10 teoksessa Doran, J.W. ym. (toim.) Defining Soil Quality for a Sustainable Environment. SSSA Special Publication No. 35.

Nuutinen, V. 1992. Earthworm community response to tillage and residue management on different soil types in southern Finland. Soil \& Tilage Research 23: 221-239. 
Palojärvi, A., Alakukku, L., Martikainen, E., Niemi, M., Vanhala, P., Jørgensen, K. \& Esala, M. 2002. Luonnonmukaisen ja tavanomaisen viljelyn vaikutukset maaperään. Maa- ja elintarviketalous 2: $88 \mathrm{~s}$.

Ricklefs, R.E. 1987. Community diversity: relative roles of local and regional processes. Science 235: 167-171.

Sippola, J., Kivistö, P. \& Mäkelä-Kurtto, R. 2001. Tutkimusasemien viljelymaiden ravinne ja raskasmetallipitoisuuksien seuranta. Muutokset aikavälillä 1992-1997. MTT:n julkaisuja, Sarja B: 27.

Terhivuo, J. 1988. The Finnish Lumbricidae (Oligochaeta) fauna and its formation. Annales Zoologici Fennici 5: 29-247.

Urvas, L. 1995. Viljelymaan ravinne- raskasmetallipitoisuuksien seuranta. Maatalouden tutkimuskeskus, Tiedote $15 / 95$. 